\title{
Urban sustainability as social innovation
}

\author{
D. Müller-Eie \& L. Bjørnø \\ Department of Industrial Economics, Risk Management and Planning, \\ University of Stavanger, Norway
}

\begin{abstract}
Implementing urban sustainability strategies has proven to be difficult. Therefore this paper aims at developing a better understanding of the urban sustainability concept as well as its relations with other concepts. The visualisation of the complex and intricate forces which constitute urban sustainability is attempted with the help of a graphic model.

The dialectic relationship between global aims and local implementation, as well as the antagonistic relationship between institutional pressure and the behaviour of individuals and communities is discussed. Also, the sometimes opposing forces in the urban sustainability concept itself are discussed, as well as the difficulties individuals face when implementing urban sustainability strategies in the light if personal disadvantages.

Due to this difficult and resistant implementation process of urban sustainability, we search for new perspectives. Here, the diffusion theory of innovations by Rogers (Diffusion and Innovation, 2003) is applied in order to approach urban sustainability as ideological and social innovation, and interpret the implementation as a socio-dynamic rather than a political or planning process.

It seems that the understanding of urban sustainability as a social innovation holds some helpful insights into why implementation so far has been difficult. Based on this individuals and their choices are proposed to become in intrinsic part of the urban sustainability concept.

Keywords: urban sustainability, individual and collective behaviour, behavioural change, diffusion of innovations, adoption, public travel.
\end{abstract}

\section{Introduction}

Almost two decades ago Jenks et al. [1] stated that there were over 200 definitions of sustainability, and it is reasonable to assume that this number has grown. A similar proliferation of definitions is true for urban sustainability, a separate 
sub-concept, where one finds over 80 definitions [2]. While it has received great attention by many disciplines (urban planning, urban design, transport engineering, architecture, building engineering, etc.), the concept is still not holistically defined and operationalised $[1,2]$. While certain parts are easy to communicate (e.g. abstract aims), other parts are rather poorly defined due to an ongoing discussion about their relevance, effect and impact of the concept (e.g. fruitful strategies and methods of implementation).

In this paper we therefore attempt to develop awareness for the complexity within the urban sustainability concept and internal sub-concepts (e.g. sustainable transportation), as well as its relationship with other concepts (e.g. climate change, global economy, social equity). The main goal is to offer a holistic understanding of the concept, since this has often been said to be a prerequisite of successful implementation [1-3]. We claim that a lack of understanding of the bigger picture leads to professional fragmented implementation, and, even more importantly, unwillingness amongst the general public to adhere to the proposed strategies (e.g. less travel, less consumption, less energy us, lifestyle changes). The current use of the urban sustainability concept is criticised mainly for:

- its weak definition and lack of operationalization;

- an under-communication of internal relationships and relationships with other concepts (as part of a complex system);

- an underestimation of the role of urban individuals and their behaviour in the implementation of urban sustainability.

We will also introduce a way of interpreting urban sustainability and its adoption by the urban population as a social innovation according to Rogers [4].

\section{What is urban sustainability?}

It is necessary to give working definition of the term urban sustainability in the context of this paper. Urban sustainability is a compound concept, which itself consist of several sets and subsets of concepts, levels, strategies and actors. Therefore, we use a divided definition:

1) Globally (aims and objectives) urban sustainability is defined as a city's capacity to meet formal, functional, social, economic and cultural standards that enable its population to live well and thrive without negatively impacting on global environmental, social and economic conditions.

2) Locally (strategically) urban sustainability can be described as the facilitation and coordination between formal and functional strategies, such as sustainable land use (compactness, intensity, density), sustainable transportation and their integration, as well as cyclic resource management.

Furthermore, the implementation of urban sustainability depends on two concepts:

a) the provision of sustainable options by urban institutions; and

b) individual and collective sustainable behaviour by the urban population.

Based on the above definitions Fig. 1 shows a graphic that intends to visualise the urban sustainability concept and its different levels. This illustration is used as a starting point for further investigation. 


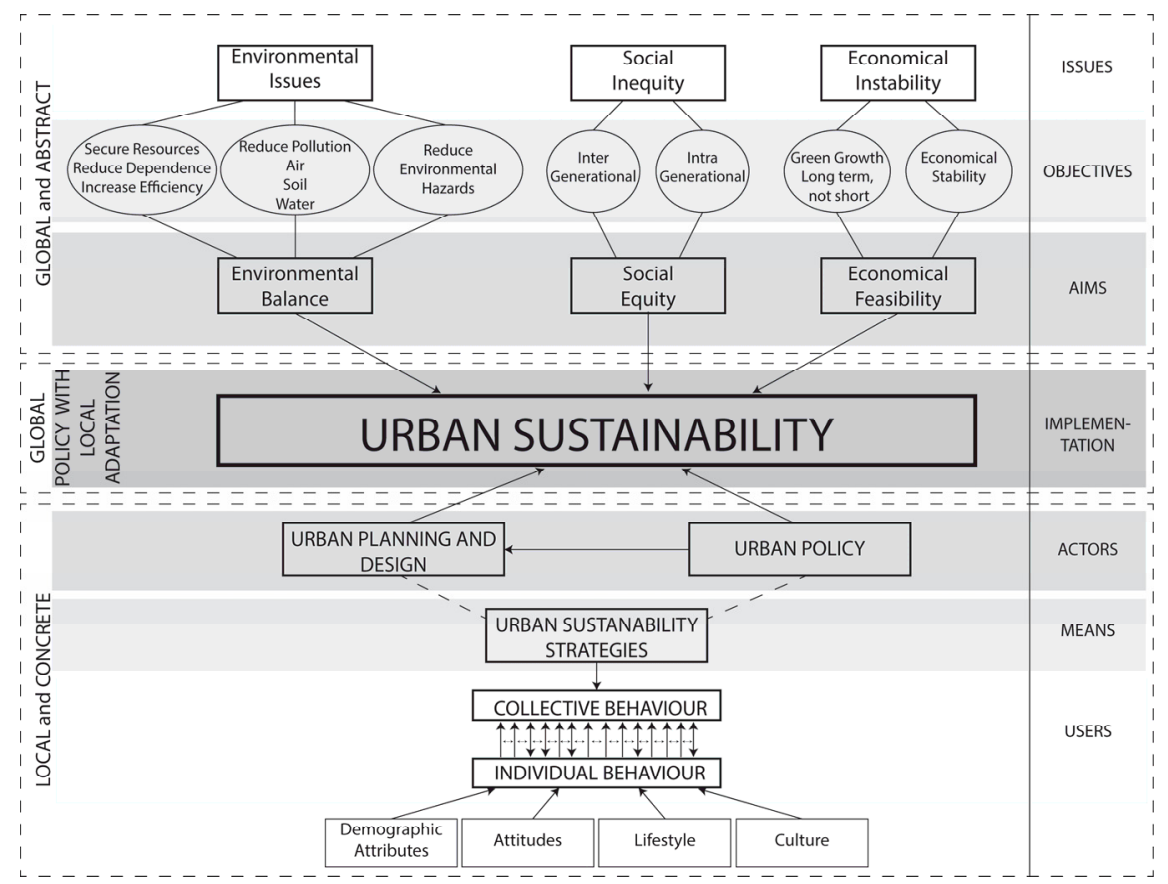

Figure 1: Urban sustainability as set of concepts and sub-concepts (authors).

Here we see how the concept is responding to external conditions: environmental issues, social inequity and economic instability. While social and environmental issues were the initial instigator for the concept, economic issues have been added to make the concept more holistic. In response to these issues, the to-be-achieved aims are often summed up as environmental balance, social equity and economic feasibility. In the sustainable development discourse, this 'holy trinity' [5] is often used as means to define the concept, without giving attention to the fact that this only defines sustainability at a very abstract and global level. Looking at existing environmental issues, such as air, soil and water pollution and depletion, dependence of non-renewable resources and their depletion, and climate changes responding environmental objectives have developed: reduction of pollution (e.g. $\mathrm{CO}_{2}$ emission), reduction of (transport and domestic) energy consumption, improved resources management, and reduction of environmental hazards. In terms of social objectives, the WCED's definition of sustainable development calls for intra-generational balance (within one generation), meaning equal opportunities for people of the same generation but possibly different nations, ages, sexes, races; as well as inter-generational balance (between different generations), meaning equal opportunities for future generations to access the earth's resources [6]. Finally the economic objectives of economic stability and green growth have been included.

Some of these objectives feed directly into the strategies and sub-concepts, i.e. the means of implementing urban sustainability. Typically these are 
sustainable transportation (modal shift, public and soft modes of transport, integrated transport and land use), intensification (population density, compactness of the built environment, accessibility), resource management (low energy building, water management, waste management). The above mentioned means are implemented by several actors: urban planners and designers, and urban policy makers. Even more importantly, and often neglected, urban inhabitants play a large role in realising sustainable behaviour.

This paper will focus on the strategy and implementation of the concept, and not so much on how these relate to the general objectives and aims.

\section{The urban sustainability concept and its contradictions}

The complexity of the urban sustainability concept can cause complications when it comes to its application and realisation. Too much focus on the global issues can in fact lead to remoteness and indifference, while a lack of understanding of the bigger picture can lead to fragmented implementation by different professional groups. Possibly even more important, there is a lack of support by the general public for some of the implemented means, which might be caused by a lack of awareness or general unwillingness to change toward more sustainable lifestyles.

\subsection{Global aims vs. local implementation}

One of the most conflicting conditions regarding the urban sustainability concept is that the importance of urban sustainability emerges in a global perspective and urgent relief of environmental issues is dictated by scientific evidence. At the same time, climatic changes can to a large extent be related to human activities, i.e. individuals. This demands action in places and by individuals that have not necessarily felt the effects of the problem. This discrepancy between global evidence and necessity for local alleviation without support from, the broad public is partly what causes slow progress [7].

There is also a discrepancy between human emotion and scientific rationality. Human nature is such, that change is difficult; even more so when the change is not initiated by ourselves but dictated by external forces. Without immediate feeling of inconvenience humans are unlikely to make drastic changes. However, there are examples where humans adhere to change based on rationality and external forces. Take the example of smoking: for some the scientific evidence of negative health impacts is enough to not start. For others this argument will not be enough to change the negative habit. However, the choice is also highly impacted by social and cultural views around smoking. So, while negative behaviour can be overcome through rationality, personal benefits from changing the behaviour are needed.

\subsection{Institutional change vs. individual change}

As an intricate, complex and all-encompassing concept like urban sustainability would warrant, there are many different groups of actors involved. In academia, a plethora of descriptive and normative research is generated knowledge regarding 
the current state of the environment as well as proposals on how to intervene $[1,8-10]$. However, often the focus is slim and neglects to view the problems and solutions as part of a whole. Particularly much of the normative research is nonconclusive or contradictory. Are higher population densities sustainable $[11,12]$ ? Is integrated land use and transportation the best way forward [13]?

When these findings are introduced and infiltrate urban policies and urban planning, several stakeholders with different a professional interest, culture, language and tools have to collaborate. Urban sustainability strategies are therefore sometimes implemented without a deep understanding for how they relate to the desired objectives and without concern for local context and culture. Also, many strategies aim at changing individual behaviour. While urban policy operates with positive and negative incentives, much of planning and design practice is based on the tacit assumption that physical environment can manipulate and facilitate certain behaviour. So far the facilitation of certain services and behaviours has not shown to be strong enough a tool to outweigh individual values, choice and concern for convenience.

If the change of people's behaviour is a prerequisite for the successful implementation of urban sustainability, we argue that people need to be taken into account as a relevant factor. While trying to change collective behaviour, the individuals that make up the collective behaviour system $[14,15]$ might not at all be interested in or even aware of their impact on the greater whole [16]. Collective behaviour can be impacted through physical provision, policies, and law; while individual behaviour is more intricate and factors in personal attributes (income, social status, household structure), attitudes and culture (value and belief systems). The urban population, not only as a whole but as a compound of individuals, has to receive greater attention.

\subsection{Strategic modal shift vs. individual desirability}

The above point is exemplified in the opposing political pressure for a modal shift from car transport to more public and soft modes of transport, and the individual choice between car and public or soft travel.

From an urban sustainability point of view there is no arguing that a significant modal shift is beneficial if not necessary. Reduced car use would reduce fueldependency, emission, the need for parking space (and thereby valuable land), noise pollution, alleviate congestion and possibly contribute positively to road safety. More passengers in public transport would also make it more beneficial to re-invest in the public transport system and offer better coverage and services. In terms of urban life, a higher rate of walking (as part of public transport journeys) activates streets and makes for a more liveable and active urban environment, as well as it supports local economy. Possible drawbacks of modal shift could be that public transport becomes crowded which reduces efficiency, and direct and indirect revenue from car ownership and use might decrease. However, from an institutional point of view the advantages of modal shift are clear.

For the individual, however, it is different. While rationally most people are aware that it is beneficial for the 'greater good' if they decide to take the bus instead of the car, it is difficult to see personal benefits. Public travel is most likely 
to take longer, include walking (i.e. health and weather dependent), be less comfortable, possibly subject to interchanges, and there might be problems with punctuality or coverage. There might be a financial gain, when one factors in the cost of car ownership. However, it is not necessary to sell a car in order to take the bus, in which case one might be inflicted with initial cost, road tax, insurance and occasional fuel cost, in addition to the cost of public travel. Based on data collected in Freiburg and Stavanger (Fig. 2), urban individuals priorities reliability and accessibility when choosing their mode of transport [17]. Travel cost seems more important in Freiburg than in Stavanger, which might be due to a relative wealth in Stavanger. The most prioritised attributes (accessibility, reliability, duration, comfort) are easier achieved through car travel, while public travel does not cater toward them and holds otherwise few personal advantages.

So, while the relevance of modal shift is clear on a political level and even rationally appraised by the individual, it is difficult to support such a large lifestyle change on a personal level in the face many disadvantages. This contradiction between institutional rationality and individual emotional response is a problem in the implementation of urban sustainability strategies.

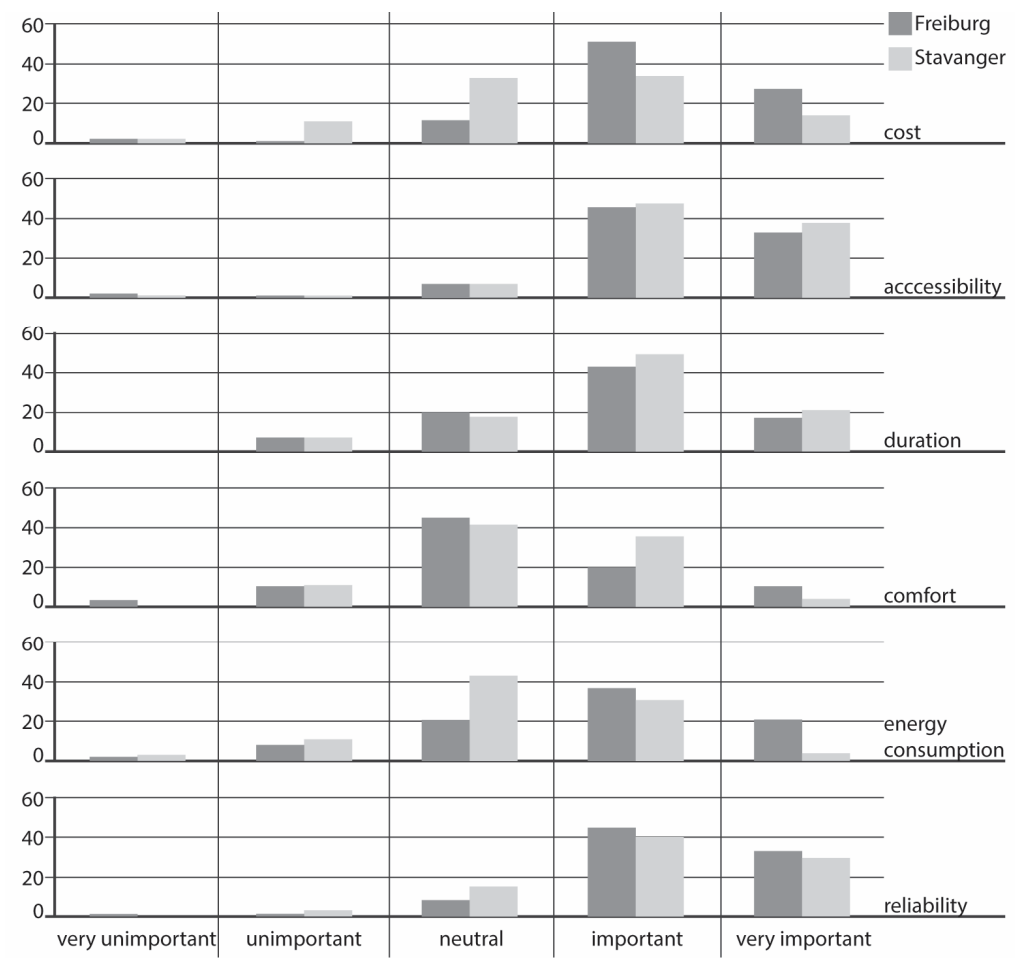

Figure 2: Important attributes of transport mode choice in Freiburg and Stavanger (Müller-Eie, 2012 [17]). 


\subsection{Attitudes vs. behaviour}

There is also a discrepancy between attitudes and behaviour. While there might be a general positive attitude towards urban sustainability, this does not necessarily result in displaying the respective sustainable behaviour [3, 18]. Knight describes this as being positive towards saving 'the environment' but sceptical towards interfering with 'my environment' [19]. Research shows that awareness and information are not sufficient in changing behaviour, but only in changing attitudes [3]. According to Owens and Drifill [3], price, awareness, trust, commitment, moral obligation, cultural norms, routines, social networks, fashion, comfort and convenience are all factors that impact individual behaviour. So, in order to effectively manipulate individual behaviour the sustainable choice must be the easiest. If reliability, accessibility and short travel time are among the most decisive factors for travel mode choice (Fig. 2), then public transport systems should be designed to facilitate this. While information can have an impact on both domestic and transport energy consumption [20], awareness campaigns will have to be combined with a change in designing the desired services. As argued for below, information is regarded the first step in adopting new attitudes, which in turns can lead to adopting new behaviour [4].

\section{Urban sustainability as (social) innovation}

Achieving urban sustainability without broad public support will be difficult. Despite urgent scientific evidence [21], people first need to appraise this 'new order' (innovation) in order to participate in immediate and drastic action. Positive attitudes are not enough; people must behave in a more sustainable way. To support this argument and give an insight into our view of urban sustainability, the theory of diffusion as known in communication theory is applied. Here, we encourage the view of urban sustainability as an ideological innovation rather than a pragmatic concept.

According to Rogers [4], "an innovation is an idea, practice, or object that is perceived as new by an individual or other unit of adoption" [4, p. 12]. This is also true to a large extent for urban sustainability, which is a new theoretical framework upon which urban practice is based. However, while a collective behavioural change at the macrolevel might be beneficial for the environment, society or economy, it might not be beneficial to each individual [16]. Rogers distinguishes between the collective and the individual as well: the individual goes through a process of adopting new behaviour, while the sum of changes is visible in the diffusion process, which leads to reaching a critical mass of adopters which makes the process of diffusion self-enhancing.

For an innovation to spread it takes "communication through certain channels over time among the members of a social system" [6, p. 11]. The rate of adoption seems to depend on certain attributes of the innovation: an innovation is more likely and quickly to be adopted if it promises advantages compared to previous behaviour, is compatible with existing values and beliefs, is simple, can be tried out and its effect can be observed [4]. Many sustainable behaviours lack relative 
advance and compatibility, and the concept itself and its implementation is all but simple (Tab. 1). Current lifestyle trends are often seen to be the cause of environmental problems [17, 22, 23].

Table 1: Relative advance, compatibility, complexity, trialability and observability of urban sustainable behaviour (authors).

\begin{tabular}{|l|l|}
\hline Relative advance & Urban sustainable behaviour \\
\hline Compatibility & $\begin{array}{l}\text { Most sustainable behaviours reduce convenience and time efficiency. } \\
\text { Some sustainable behaviours are more attractive through financial } \\
\text { incentives. }\end{array}$ \\
\hline Complexity & $\begin{array}{l}\text { Urban sustainability is not compatible with individualism and } \\
\text { pragmatism. However, sustainable behaviour can make use of social } \\
\text { desirability (e.g. the wish to be seen to care). }\end{array}$ \\
\hline Trialability & $\begin{array}{l}\text { The many layers and relationships between local strategies and global } \\
\text { objectives are not necessarily straightforward. }\end{array}$ \\
\hline Observability & $\begin{array}{l}\text { It is easy to try out sustainable behaviour such as urban travel, but not } \\
\text { the for instance for the choice of place and mode of residence. }\end{array}$ \\
\hline & $\begin{array}{l}\text { Sustainable behaviour amongst others is observable, but the effect is } \\
\text { unlikely to be visible on a local level. }\end{array}$ \\
\hline
\end{tabular}

Communication as the main tool in the socio-dynamic process of diffusion of innovations can be related to using information in order to enhance awareness in urban sustainability [24]. The process of adoption has five stages: knowledge, persuasion (positive or negative attitude), decision (acceptance or rejection), implementation (use) and confirmation [4]. Furthermore, time is seen to be an important element in this process; both the time it takes for a member of the social system to adopt the innovation (individual) and the time it takes for the innovation to achieve a critical mass (collective).

Rogers also suggests four strategies to reach critical mass faster: adoption amongst high-profile individuals, description of inevitability of critical mass or faking achieving a critical mass, achieving critical mass amongst a target-group, and offering incentives for adopting [4]. Whether or not the level of information and awareness, the modes of communication and positive and negative incentives are effective in changing people's behaviour remains uncertain, and further research into this is needed.

\section{Public travel as part of the urban sustainability innovation}

\subsection{Diffusion of public travel as a urban sustainability concept}

The adoption of public travel as part of the urban sustainability innovation is further investigated with the help of data from Freiburg (Germany) and Stavanger (Norway).

When talking about the state of diffusion of public travel as an idea, it is with regard to collective dissemination of public transport as main mode of transportation. It is obvious that more people regularly travel publicly in Freiburg than in Stavanger (Fig. 3). 
The communication about public travel seems to be quite different in these cities: While the importance of public travel is conveyed in both cities in political documents [25, 26], Freiburg's public transport system with its affordable and transferable Regiokarte is frequently referred to as one of the most successful examples in academia [27] (channels). A major difference between the cities is the timeframe in which urban sustainability has been on the agenda. Freiburg has been environmentally proactive since the $80 \mathrm{~s}$, while Stavanger has only recently set focus on sustainable transport. With its 'green' government Freiburg has gained the reputation of being Germany's environmental capitol, while Stavanger functions as the oil capitol in Norway. These identities are deeply embedded in the social and cultural structures of both cities. Thus, it seems that a long-lasting and positive diffusion of the urban sustainability ideal is a prerequisite for individual and collective adoption sustainable behaviour.

\subsection{Adoption of public travel behaviour}

In academic circles knowledge and information regarding modal shift has existed for several decades [27-29], and is backed up by recent reports of adverse environmental impacts of ever-increasing $\mathrm{CO}_{2}$ emission [21]. But is this information also conveyed to urban individuals in a clear and understandable way? Most likely, political commitment to $\mathrm{CO}_{2}$ reduction and the resulting advocacy of public travel are the first information urban individuals receive. It is therefore possible that the persuasion stage is forged by unexplained and forced action with can lead to ambiguous attitudes toward public travel.

Whether he or she travels by car or by public transport becomes the implementation of this internal process of adoption. First now we can empirically measure the adoption of public travel among a certain population in terms of displayed travel behaviour. Fig. 3 shows that Freiburg's population shows a more sustainable travel patterns, i.e. more public transport. Whether inhabitants continue to travel publicly depends on their experiences with public travel, i.e. whether public travel as a beneficial behaviour is confirmed or not.
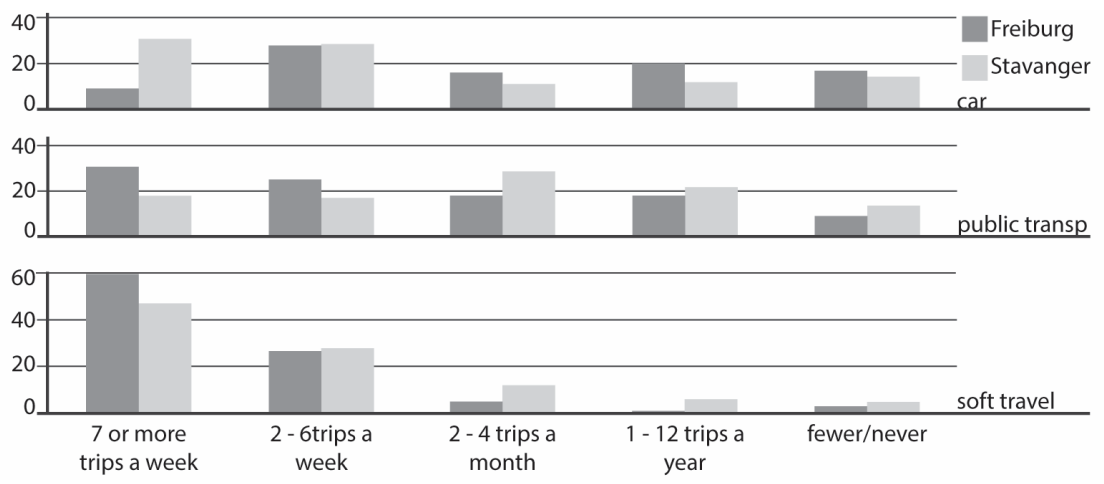

Figure 3: (Self-reported) public travel frequency in Freiburg and Stavanger (Müller-Eie, 2012). 
It seems that sustainable travel is more readily implemented in Freiburg than in Stavanger. While travel behaviour reflects many contributing and intervening factors, such as urban layout, public transport network, together with personal and cultural attributes, we can assume that individuals are further in their personal adoption process, and have collectively contributed to reaching a critical mass for public travel in Freiburg.

\subsection{Rate of adoption of public travel}

Introducing public travel is an ongoing and slow process. When reviewing Rogers' five attributes for adoption rate, it becomes apparent that only some of these attributes apply.

Public travel is highly observable. It happens in public space and is part of everyday urban life. Thus, observing many people displaying public travel behaviour works as an attracting force. However, there is a point of saturation where too many passengers become off-putting. In terms of trialability, one does for instance not have to give up car travel in order to travel publicly (they are not mutually exclusive), which allows for non-committing trial.

When it comes to public travel's advance, compatibility with previous behaviour and complexity, it is obvious that public travel is neither perceived as advantageous nor simple. The impact of an individual's choice to use public transport instead of the car is marginal for the global environment, and public travel is only one of many behavioural changes that form the desired sustainable lifestyle. Changing from daily car to public travel also requires a great change of routines, i.e. is not compatible with previous behaviours or experiences. On the individual level, there are few advantages compared to car travel. One is likely to spend more time, be less comfortable and be more exposed to weather than previously. The positive effects of public travel might be not having to find a parking lot and the possibility of socialising or reading during travel. If one also opts out on owning a car, transport costs (car ownership, road tax and fuel) are reduced and the need for maintenance and a home with parking opportunity becomes redundant.

Despite the fact that personal advantages and compatibility are the most important factors in adopting a new behaviour, the change from car travel to public travel holds few individual benefits and is little compatible with current lifestyles. However, the environmental benefit from a collective shift from the private car to public transport is understandable and a possible driving force for behaviour change.

\subsection{Intervening action to facilitate public travel}

In order to get people to reduce car travel and increase public travel, several incentives have been suggested. An increase in road tax and fuel price has often been proposed as one of the most effective ways to achieve modal change [28, 30]; this is often combined with strict parking regulations, a reduction of parking spaces and an increase in parking cost. In addition can public transport be subsidies to achieve more affordable tickets, which has been said to be the main factor for 
the success of the Regiokarte [27]. However, the recent study of Freiburg and Stavanger has shown that financial incentives are not equally effective in affluent populations [17].

Thus, effective intervention for getting people to adopt sustainable travel behaviour should focus on a proactive improvement of public transport with regards to reported prioritised attributes (see Fig. 3). These local social and cultural factors must be taken into account; meaning that more affordable public transport might be effective in Freiburg while cost was not a decisive factor in Stavanger.

\section{So what does this mean for urban sustainability?}

The above presented argument shows that new perspectives and insight can be gained from viewing urban sustainability not merely as an instrument or goal, but as a social innovation. Reducing urban sustainability to a practical, political or physical concept ignores the wide-ranging impact it has on society. Rather than looking at the changes in the urban population's behaviour as a result, we must view them as an internal and essential sub-concept of urban sustainability.

Urban sustainability is still ill-defined and further research into sub-concepts and their relationships with the general aims is needed. The same is true for local action and its actual impact on paramount objectives. While much research is currently undertaken to these ends, little attention is given as far as the coordination of these efforts goes. Regardless, adhering to the precautionary principle, action is required without conclusive scientific proof [31]. The acting professions are mainly urban planning, urban design and urban policy. Currently, these professions co-exist in two independent realms (theoretical framework, tools, scales). In order to coordinate and integrate their effort, a synergy between the two disciplines is necessary.

Thus, 1) a better understanding of the contributing forces and effects in and around urban sustainability is needed; 2) effective change requires coordination between professionals and politicians; and 3) collective and individual lifestyle and behavioural change needs to be investigated and incorporated as a measure of urban sustainability implementation.

Academia, urban professions and users need to understand that urban sustainability is not another urban planning or design ideal that comes with a change of certain physical settings. It is rather a large scale change of mind-sets (i.e. a paradigm shift). This social innovation will have long-lasting impact on society and its individuals. Just remember, that while it was unthinkable to prohibit smoking in public places just a few decades ago, it has now become commonplace without people giving it a second thought. With the help of some of the above presented suggestions from prevalent understandings in communication theory, the change of collective and individual behaviour toward more urban sustainability can and must be facilitated through social and cultural sensitivity and an appreciation of the individuals influence. 


\section{References}

[1] Jenks M, Burton E, Williams K, editors. The Compact City: A Sustainable Urban Form? London: E \& FN Spon; 1996.

[2] Keirstead J, Leach M. Bridging the Gaps Between Theory and Practice: a Service Niche Approach to Urban Sustainability Indicators. Sustainable Development. 2008; 16: 329-40.

[3] Owens S, Drifill L. How to Change Attitudes and Behaviours in the Context of Energy. Energy Policy. 2008; 36: 4415-8.

[4] Rogers EM. Diffusion and Innovation. 5 ed. New York: Free Press; 2003.

[5] Findeli A. Sustainable Design: A Critique of the Current Tripolar Model. The Design Journal. 2008; 11(3): 301-22.

[6] World Commission on Environment and Development, Brundtland GH. Our common future. Oxford: Oxford University Press; 1987. XV, p. 400.

[7] Hillman M. In Favour of the Compact City. In: Jenks M, Burton E, Williams K, editors. The Compact City - A Sustainable Urban Form? London: E \& FN Spon; 1996.

[8] Jenks M, Williams K, Burton E, editors. Achieving sustainable urban form. London: E \& FN Spon; 2000.

[9] Jenks M, Dempsey N, editors. Future Forms and Design for Sustainable Cities. Amsterdam: Elsevier; 2005.

[10] Thwaites K, Porta S, Romice O, Greaves M, editors. Urban Sustainability Through Environmental Design - Approaches To Time-People-Place Responsive Urban Spaces. Oxon: Routledge; 2007.

[11] Williams K. Can urban Intensification Contribute to Sustainable Cities? An International Perspective, 2007.

[12] Breheny M. The Contradictions of the Compact City: A Review. In: Breheny MJ, editor. Sustainable Development and Urban Form. London: Pion Limited; 1992.

[13] Echenique MH, Hargreaves AJ, Mitchell G, Namdeo A. Growing Cities Sustainably. Journal of the American Planning Association. 2012; 78(2): 121-37.

[14] Williams K, Dair C, Lindsay M. Neighbourhood Design and Sustainable Lifestyles. In: Jenks M, Jones C, editors. Dimensions of the Sustainable City. Dordrecht: Springer; 2010.

[15] Handy S. Methodologies for Exploring the Link between Urban Form and Travel Behaviour. Transport Res. 1996; 1(2): 151-65.

[16] Schelling TC. Micromotives and Macrobehavior. New York: W. W. Norton \& Company; 1978.

[17] Müller-Eie D. Urban Environmental Performance and Individual Behaviour: A Comparison between Freiburg and Stavanger. Glasgow: University of Glasgow; 2012.

[18] Næss P. Can Urban Development be Made Environmentally Sound? Journal of Environmental Planning and Management. 1993; 36(3): 309-33. 
[19] Knight C. Economic and Social Issues. In: Jenks M, Burton E, Williams K, editors. The Compact City: A Sustainable Urban Form? London: E \& FN Spon; 1996.

[20] Hertwich E, Katzmayr M. Examples of Sustainable Consumption: Review, Classification and Analysis. Trondheim: NTNU, 2003.

[21] 2014. Climate Change 2014 - Mitigation of Climate Change.

[22] Weber C, Perrels A. Modelling lifestyle effects on energy demand and related emissions. Energy Policy. 2000; 28: 549-66.

[23] Vlek C, Steg L. Human Behaviour and Environmental Sustainability: Problems, Driving Forces, and Research Topics. Journal of Social Issues. 2007; 63(1): 1-19.

[24] Gauzin-Müller D. Sustainable Architecture and Urbanism - Concepts, Technologies, Examples. Basel: Birkhäuser; 2002.

[25] Freiburg. Flächennutzungsplan 2020. In: Breisgau SFi, editor. Freiburg: Stadt Freiburg im Breisgau; 2006.

[26] StavangerKommune. Kommuneplan 2010-2025. In: Kommune S, editor. Stavanger: Stavanger Kommune; 2011.

[27] FitzRoy F, Smith I. Public Transport Demand in Freiburg: Why did Patronage Double in a Decade? Transport Policy. 1998; 5: 163-73.

[28] Rickaby P, Steadman P, Barrett M. Patterns of Land Use in English Towns: Implications for Energy Use and Carbon Dioxide Emissions. In: Breheny MJ, editor. Sustainable Development and Urban Form. London: Pion Limited; 1992.

[29] Stead D, Williams J, Titheridge H. Land Use, Transport and People: Identifying the Connections. In: Williams K, Burton E, Jenks M, editors. Achieving Sustaainble Urban Form. London: E \& FN Spon; 2000.

[30] Barrett G. The Transport Dimension. In: Jenks M, Burton E, Williams K, editors. The Compact city: a sustainable urban form? London: E \& FN Spon; 1996.

[31] Wilson E. The Precautionary Principle and the Compact City. In: Jenks M, Burton E, Williams K, editors. The Compact city: a sustainable urban form? London: E \& FN Spon; 1996. 